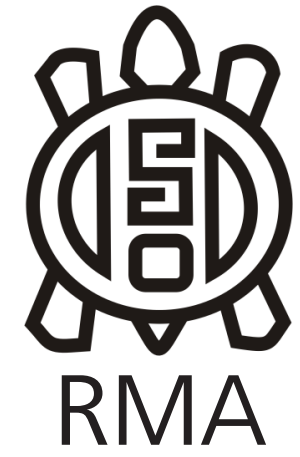

Dossier

\title{
Conversas cantadas: sobre poéticas e transformações no mundo rural
}

\author{
Sung talks: about poetics and transformations in rural society
}

Simone Silva

Professora de Antropologia Social, Departamento de Ciências Sociais, Universidade Federal Fluminense, Brasil. simonesilvabr@gmail.com

\begin{abstract}
Resumo
Este artigo busca trabalhar as narrativas poéticas na zona da mata de Pernambuco enquanto um elemento de discurso, a partir do qual pretendo refletir sobre as formas como a emoção se revela nas práticas cotidianas e na sociabilidade local. Nesse sentido, vou lidar com emoção como um fenômeno essencialmente social, tendo no discurso o lugar de sua análise. O texto tem como base o material etnográfico produzido em "ambientes" de cantoria-de-parede, a partir da minha relação com poetas e moradores dessa região. Partindo da análise de situações atravessadas por elementos de discursos como poemas, glosas e canções improvisadas, os quais são tomados aqui como elementos analíticos privilegiados devido a sua importância e centralidade na dinâmica social, pretendo avançar na reflexão sobre a percepção local de tempo e, simultaneamente, demonstrar como essa noção está intimamente entrelaçada pela experimentação poética que é peculiar a toda essa região. Para tal, vou tentar relacionar o conceito de versura, e o intervalo que lhe é característico, ao conceito de tempo como oscilação de opostos, igualmente marcado por um hiato. O ponto de interseção dessa correlação que guiará a análise sobre a noção nativa de tempo é justamente a profusão de sentidos que emerge nesse intervalo.
\end{abstract}

Palavras-chaves: poesia, emoção, Pernambuco, sociabilidade, etnografia

\begin{abstract}
This article seeks to analyse the poetic narratives in Zona da Mata of Pernambuco as a speech element, whereby I intend to reflect on the ways in which emotion is revealed in daily practices and sociability. In this sense, I will deal with emotion as an essentially social phenomenon, considering the discourse the place of its analysis. The text is based on ethnographic material produced in "ambientes» of cantoria-de-parede, through my relationship with poets and residents of this region. Considering ethnographic stiuations crossed by elements of speeches, for example, poems, glosses and improvised songs, which are taken here as privileged analytical elements because of its importance and centrality in the social dynamics, I intend to go forward the reflection on the local perception of time and simultaneously demonstrate how this notion is closely connected to the poetic experimentation that is peculiar to the region. To do this, I will try to relate the concept of versura, and the gap that is its main characteristic, with the concept of time as opposed oscillation, also marked by a hiatus. The intersection point of this correlation that will guide the analysis of the native time is precisely the multitude of meanings that emerge in that gap.
\end{abstract}

Keywords: poems, emotion, Pernambuco, sociability, ethnography

Há alguns anos, em meio a uma conversa informal sobre família, um ex-funcionário da extinta Usina Matary, recitou o seguinte poema:

Moagem

A cana no campo

A palha secando úmida

O homem da foice

e o corte a doidado

O canto do canavieiro acurralado

A cana queimando

A foice cantando

O feixe amarrado

O jogo do rito

A cor do salário
O caminhão na estrada
A buzina no mundo
A carroceria lotada
O tempo encurtando
O ritmo segue
O carro dançando
A longa corrida
Com pé na tábua
O peso da cana
A cana pesada
A balança da usina
Com o jogo para lá e para cá
Guincho esperando

A cor do salário

caminhão na estrada

A carroceria lotada

O tempo encurtando

O ritmo segue

A longa corrida

Com pé na tábua

O peso da cana

A cana pesada

Com o jogo para lá e para cá

Guincho esperando 
Guincho rangendo

Guincho chorando

Guincho sofrendo

Guincho deitando

Guincho gemendo

Guincho temendo

Guincho correndo

A carga de cana

O jogo incessante

O despejo na esteira

O embaraço das canas

A luta pela sobrevivência

A luta de cada um

A navalha sedenta

A moeira gritando

E o lamento das moídas

$O$ zigue-zague horrendo

A dança da morte

A resistência dos gomos

A moída correndo

e a navalha cortante

As partículas adocicadas

As canas espatifadas

As canas espremidas

As canas estraçalhadas

As canas prensadas

As canas chorando

O bagaço espalhado no chão

O operário vencendo o tempo

O tempo tão curto

A cana mijando

O xarope fervendo

O caldo e o xarope

$O$ tanque imenso

O calor infernal

A caldeira palpitante

O fogo trepidante

O bagaço queimado

$O$ vapor infernal

Cano quente

Vapor encanado

Xarope cristalizado

A massa nos [...]

O mel nascente

O mel açucarado

O melaço no tacho

E o miolo separado

O mel pobre

Em tanques pobres

O mel rico

Vem nas turbinas

O giro doido das cascas

A turbina apressada

O giro giratório girando

O açúcar açucarado

A bica de espiral rodando

O açúcar e o calor

O açúcar, o funil

O açúcar cristalizado
O açúcar ensacado

O mel pobre na destilaria

O fabrico do álcool

O cheiro no ar

O lucro no bolso

O patrão orgulhoso

O dinheiro no bolso

O odor sempre forte

A cana

O caldo

O mel

O açúcar

O álcool

O berro da sirene

O operário fatigado

A rede esperando

O corpo cansado

O progresso no mundo

O açúcar tornou-se

$\mathrm{O}$ destino do homem

Às vezes tão amargo

(José Antônio da Silva, Goiana, 2005)ำ

Os versos acima emergiram como reflexão sobre as condições degradantes e desumanas às quais o poeta e a sua família estiveram submetidos enquanto operários da usina. Natural de Goiana - mata norte de Pernambuco, o senhor José Antônio "criou-se na Usina Matary", onde viveu até os seus 18 anos de idade. Chegou a trabalhar por cinco anos nesse ofício, mas logo após a morte de seu pai, ele foi dispensado e resolveu, assim, ir para São Paulo. Completou o magistério e fez faculdade na capital paulista, e nessa ocasião, além da carreira como educador, passou a acumular prêmios como poeta. Os seus pais nasceram, foram criados e morreram em engenhos da região, especificamente nas cidades de Nazaré da Mata e Condado. Ao recuperar a memória do tempo em que vivia na Usina Matary, ele ilustra, por exemplo, a reação "da turma" (referindo-se aos operários), no dia em que "o patrão" comprou uma máquina considerada moderna para época, que viria a ser manipulada pelo seu pai:

Meu pai era maquinista. Apareceu uma máquina lá moderna. Aí a turma inventou um verso:

A máquina quando desce lá na serra,

Caçoando toda moderna

o apito faz chorar

O maquinista é Zé Clementino [...].

Descendo a zona da mata, indo em direção à cidade de Vitória de Santo Antão, encontra-se o senhor Raimundinho que, nesses dez anos de pesquisa na região, foi um fiel interlocutor, sempre disposto a conversar, apesar de sua timidez que por vezes me desorientou em silêncios. 0

\footnotetext{
${ }^{1}$ O poema foi recitado e, posteriormente, transcrito por mim. PeçoIhes desculpe por alguns versos incompletos, pois havia muito barulho no local onde a conversa transcorreu, e, sobretudo, porque a poesia como um todo, certamente, pela pouca habilidade com as regras de construção da métrica silábica acentual, pode ter algum erro de composição. Assumo aqui a responsabilidade total dessa transcrição.
} 
agricultor, hoje com 67 anos, morador do sítio Uruba, estudou até a quarta série do ensino básico; é dono de uma pequena casa de farinha e conhecido por organizar "brincadeiras"2 - fato esse que, na região, enaltece o chefe de família. Certo dia, trabalhando nos canteiros de hortaliças, ele me explicou que o intervalo da plantação parecia a transição de um verso poético a outro, e reiterou: "Não parece? O verso do cantador vai até o final e volta. Entre um verso e outro, encontra-se a turma". Eu então com o rosto suado pelo forte calor que fazia, e as mãos cheias de hortaliças, devolvi-Ihe a pergunta: "Mas as plantas desabrocham e crescem, e os versos, eles não acabam na brincadeira?". Ele me retribuiu o sorriso, ajudando-me com o já insustentável ramo de coentro que eu carregava, e explicou: "Simone, venha cá. Largue isso aí. Você está vendo esse morrinho? Ele vem aqui, faz a curva e continua no outro, não é isso? Nós estamos aqui colhendo os coentros em morros paralelos que vão de um lado a outro, percebe? É um ziguezague, não é? Pois bem, isso aqui é como os versos que a gente escutou no sábado com a turma. O bom poeta faz verso que dura até a próxima colheita. O bom agricultor também". Essa observação, que sempre me pareceu bastante instigante, mas que até então só conseguia lhe ver a partir de uma correlação metafórica da eficácia do triângulo Deus-Homem-Terra (Woortmann, Ellen. 2009) no que concerne à percepção moral da relação do homem do campo com a terra e com os demais, passou anos em meu caderno de campo, sendo muitas vezes atualizada em visitas posteriores, sem que eu soubesse bem o seu lugar no universo analítico sobre a poética da zona da mata. Em algumas dessas visitas, em especial, durante o trabalho na roça em dias que antecediam ou posteriores à realização de uma cantoria, as conversas com muitas outras pessoas, além daquele aqui já citado, traziam novos elementos para a comparação metafórica entre agricultura e poesia e aludiam aquilo que Brandão (1981) chamou de ethos camponês. Pois bem, anos mais tarde, conversando com um colega especialista em crítica literária e estudioso de latim, deparei-me com o conceito de versura:

"Termo latino que designa o lugar em que o arado dá a volta no fim do campo. Existe um paralelismo com

alguns sistemas de escrita antigos, nos quais as linhas corriam alternadamente da esquerda para a direita e da direita para a esquerda, como acontecia na escrita grega antiga..." (Agamben, 1999:30)

A versura, manifestada no fenômeno literário conhecido por enjambement ${ }^{3}$, conserva como característica central

\footnotetext{
${ }^{2}$ Na zona da mata pernambucana, chama-se de brincadeira reuniões organizadas em casa, por amigos e parentes, em torno de algum motivo específico: celebração de aniversário, cantoria de pé-deparede, um coco-de-roda para alguma celebração familiar, etc. Tanto os seus organizadores quanto os convidados agem na "brincadeira" a partir de um contexto de incertezas quanto ao dia de sua realização, ao momento de seu encerramento, à presença dos convidados, no caso da cantoria, quanto às narrativas poéticas que serão expostas, o que implica em sua característica mais marcante: a improvisação. Toda brincadeira é um improviso. Ela se faz numa temporalidade que é por ela mesma construída.

${ }^{3}$ Trata-se de um processo poético que consiste no desalinhamento da
}

o movimento díspar: vai de frente para trás, de trás para frente; ela constitui o cerne do verso e é a condição necessária e suficiente da versificação. Na continuidade de um verso a outro, abre-se um intervalo do e para o sentido. Vejamos um exemplo:

\section{O açúcar tornou-se}

O destino do homem

Às vezes tão amargo.

Retornaremos mais adiante ao fenômeno da versura e à metáfora do canteiro utilizada pelo senhor Raimundinho.

A casa de farinha, localizada, em geral, no terreno residencial de seu proprietário, desde os tempos dos engenhos, é uma alternativa importante para a complementação da renda familiar, devido à centralidade desse alimento na cesta básica da região. Além disso, esse espaço da casa é o lugar de descontração, brincadeiras, fofocas, poesia e histórias, que juntos criam uma atmosfera de autonomia para os trabalhadores (Silva, 2010; Scott, 1992). Na casa de farinha reúnem-se mulheres e homens do núcleo familiar e, às vezes, vizinhos e parentes, uma vez por semana. Os homens são encarregados das atividades que exigem mais força física, por exemplo, o manuseio da prensa da mandioca, enquanto as mulheres cuidam do forno. Quando um chefe de família proprietário de uma casa de farinha organiza uma brincadeira, em especial uma cantoria de pé-de-parede, é lá que ela ocorre, corroborando a ideia de ser o lugar da autonomia, e aqui estamos pensando-a para além das condições necessárias à reprodução econômica da população, e do rito sazonal da descontração.

O senhor Beija-Flor, ex-agricultor, membro fundador do Sindicato dos Trabalhadores Rurais de Paudalho, já foi

estrutura métrica e sintática de uma composição, onde os versos se sucedem entre si sem pausas no final de cada um.

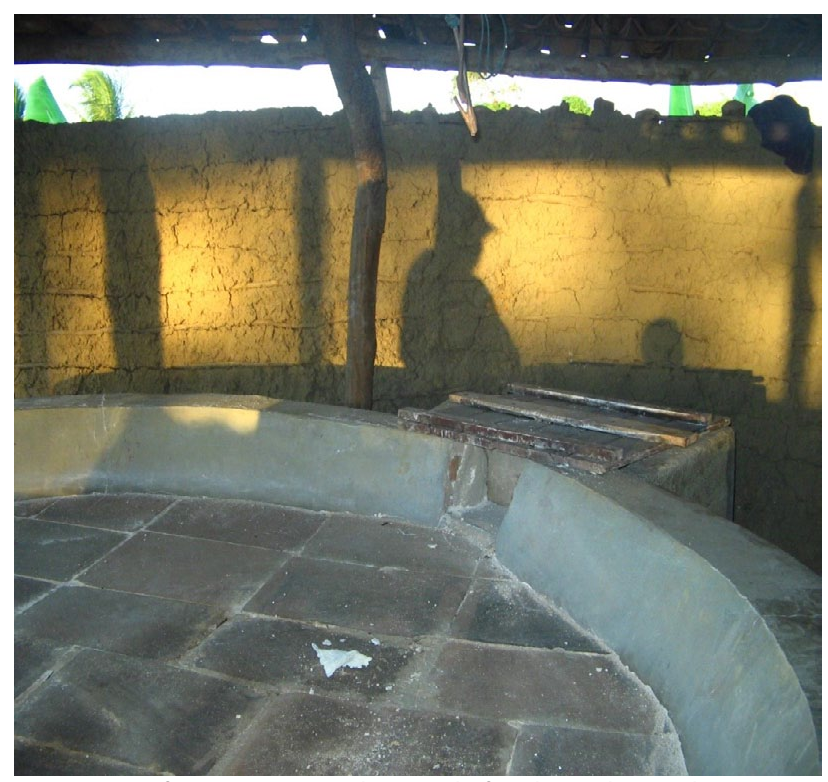

Figura 1. O forno no centro da casa de farinha - Sítio Uruba

Figure 1. The oven in the center of the flour house - Sítio Uruba 
vice-prefeito de sua cidade, funcionário da Federação dos trabalhadores na agricultura do estado de Pernambuco (FETAPE) e poeta, em longas conversas sobre o tempo em que era morador de engenho, sempre fez questão de descrever minuciosamente os encontros da turma na casa de farinha de seu vizinho Luiz.

“Ele (referindo-se ao Luiz - um velho amigo e também morador do engenho) já era um cidadão com uma situação mais melhorada que a minha. Eu era um filho sem pai. Meu pai tinha deixado a gente quando eu tinha treze anos de idade. Era eu quem sustentava a família. Tinha a vida muito sacrificada. Ele tinha a vida mais folgada, casado com filho e com tudo. Ele explorava farinha de mandioca. Ele fazia farinha de mandioca. E tinha noite que ele me convidava para eu ir para a casa de farinha para eu fazer uns versos lá. Cantar de improviso lá. E eu ficava cantando... não tinha viola. Eu pegava era uma trava de porta botava no peito, como se fosse um violão ou uma viola, e ficava cantando, entretendo o pessoal que estava raspando mandioca, para não dormir cedo. E raspava era mandioca. Eu não entendia que eu estava explorando as pessoas. Ajudando, né? Eu não estava explorando, eu estava sendo explorado. Eu não entendia que o companheiro estava me explorando e explorando as companheiras que estavam raspando mandioca... Ele não pagava não. Era só para ajudar. E eu ficava ali enganando o povo. O povo não dormia e toma é mandioca. Depois de muito tempo que eu descobri: eu explorado e ajudando a explorar os outros. Ele dizia: "um dia, eu vou comprar uma viola para dar a você". E nunca comprou essa viola."

(Poeta Beija-Flor, Paudalho, 2006)

Esses três casos, propositalmente apresentados de forma desconexa, vividos por pessoas com trajetórias diferentes, momentos díspares e em cidades distintas, são exemplos extraídos de inúmeras outras situações que exprimem a linguagem poética na região da mata pernambucana. A poesia, que outrora, na história do Ocidente, confundia-se com a filosofia, é aqui uma prática de fala/um discurso que coincide com a forma como as pessoas se concebem nesse mundo. São muitos os gêneros poéticos dessa região, muitos dos quais, mesmo depois de dez anos, eu não me aventuro a falar por tamanha complexidade; inúmeras são as manifestações artísticas que tem a narrativa poética como base de sua performance; de forma semelhante, incontáveis são as pessoas que tem a habilidade de versificar, mesmo não sendo consideradas como poetas profissionais, que, por sua vez, abundam e compõem a paisagem tanto quanto os canaviais. Recuperando o caso da compra da máquina moderna da Usina Matary, as pessoas contam novidade, criticam, riem e choram em versos. Fofocas, intrigas, declaração de afeto entre familiares, desavenças de vizinhos, campanha eleitoral, propaganda do comércio local, divulgação de programa do governo federal, entre tantos outros fatos ordinários da vida cotidiana são perpassados pela experimentação dos versos. Deve-se a isso a grande quantidade de trabalhos já produzidos sobre maracatu rural, coco de roda, teatro de bonecos, e etc. Assim, a abordagem sobre cantos, narrativas e seus similares do Nordeste brasileiro configurase como uma espécie de enseada para aquele que nela deseja mergulhar. Pela profusão de muitos trabalhos já feitos, e nas mais variadas chaves analíticas, torna-se um grande desafio conduzir o leitor da serenidade da baía, circundada pelos sólidos montes de estudos folclóricos clássicos, por ensaios de pesquisadores orgânicos, ou ainda, por trabalhos tipológicos e/ou enciclopédicos, a um mar de paisagens inexploradas.

Entendendo como um desafio qualquer que seja o estudo sobre o universo poético acima exposto, trago então como proposta lançar luz a um sendeiro que acredito ter considerável singularidade em relação aos demais trabalhos: refletir sobre a poética a partir da sociabilidade no mundo rural. Pernambuco, como todo Nordeste brasileiro, é feito em versos. Desde as narrativas dos colonizadores e missionários, que compuseram a imagem de "povo descoberto" (Bianchi, 2001), às disputas regionais do começo do século $X X$ pela consolidação de uma narrativa genuinamente brasileira (Silva, 2002), o Nordeste vem disputando a retórica num processo em que ele é simultaneamente o sujeito e o objeto da construção. Por outro lado, a consolidação de uma estética da dor e do sofrimento pelos grandes ciclos da seca compõem paisagens densas de personagens, que antecedem e ultrapassam as folhas de ciclos literários, e são ressignificados em narrativas cotidianas, em intrigas familiares, na valentia do fazer-se adulto, na virilidade "do cabra macho"; o cangaço, por exemplo, tema recorrente nos folhetos de cordel e nas glosas das brincadeiras, é atualizado cotidianamente na dramatização da valentia, nas disputas políticas e nas alianças. Francisco das Chagas

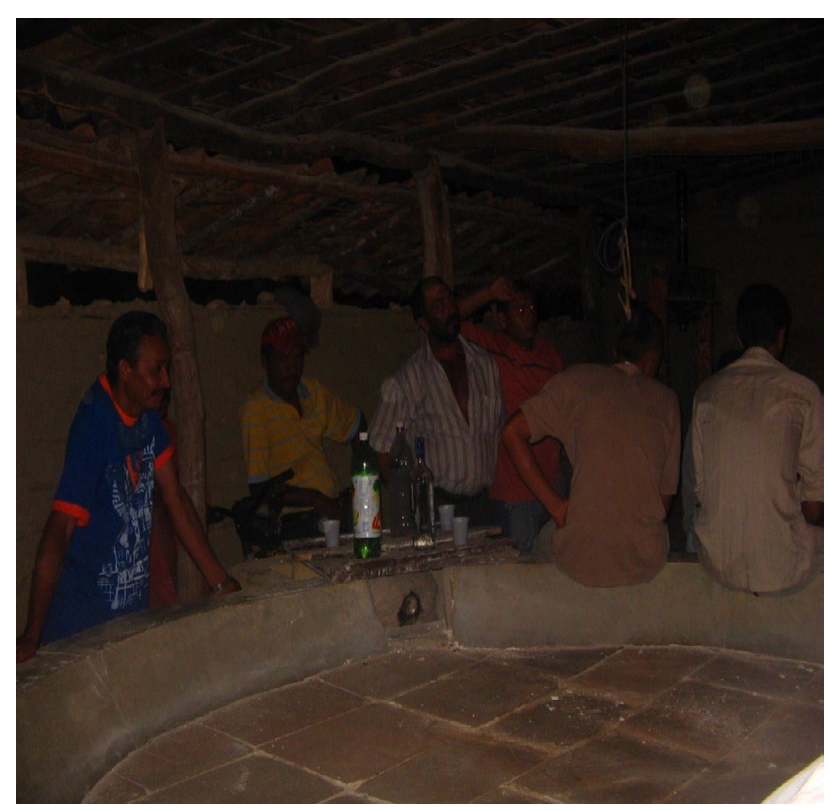

Figura 2. A casa de farinha em dia de cantoria

Figure 2. The flour house in day of cantoria 
Batista, ao descrever o sertão, recupera aqueles que ele considera como personagens centrais dessa paisagem:

Ali se aprecia muito

Um cantador, um vaqueiro

Um amansador de poldro

Que seja bom catingueiro

Um homem que mata onça

Ou então um cangaceiro.

Do sertão à zona da mata, as máscaras dos caretas sertanejos, os caboclos e os bonecos mamulengo levamnos a uma dimensão de sentidos obscuros. Na hibridez homem-animal, esses personagens constituem medos, alegrias, vergonhas, personificando seres inanimados que, em versos, vão constituindo e alinhavando afetos e emoções. Diante desse enorme quadro de elementos de discurso, a análise aqui proposta pretende fugir ao clássico esquema analítico de tomar o ritual como o lugar que permite a expressão e o extravasamento de emoções pré-existentes, transformando, desse modo, a emoção em processos psicobiológicos que nos retem uma essência intocada pela dimensão social. Acredito que a análise sobre a expressão da emoção através da linguagem, tomada aqui pelo discurso, é fundamental para compreender o papel que a retórica exerce na formação e na perpetuação das relações sociais (Abu-Lughod \& Lutz, 2008). Nesse sentido, lidarei com emoção como fenômeno essencialmente social, com as emoções como fenômenos essencialmente sociais, tendo no discurso o lugar de sua análise. Por outro lado, em face à enorme variedade de uso do vocábulo discurso, o que culminou na impossibilidade de definição do termo, cabe assinalar que estou lidando com a concepção de Foucault, ou seja, o discurso enquanto práticas que formam sistematicamente os objetos dos quais eles falam. Assim sendo, a emoção será tratada enquanto categoria etnográfica e todos os elementos de discurso aqui trabalhados - motes $^{4}$, canções, poesias, que nesse texto estão atrelados ao contexto da cantoria de pé-de-parede, estão sendo vistos como práticas sociais e, consequentemente, veiculados às dinâmicas de sociabilidade. Vale ainda ressaltar que o leitor se deparará com dois empregos do vocábulo poética: o primeiro deles como adjetivo qualificador das improvisações - o gênero poético em si, e o segundo como sinônimo de ação. (Herzfeld)

\section{Acorda camponês! Cinco horas da manhã, acorda camponês!}

A zona da mata de Pernambuco é toda área localizada entre o planalto da Borborema e o Oceano Atlântico. A parte norte é seca, devido a pouca influência da encosta da Borborema, enquanto o sul é úmido. A região é marcada pela plantation canavieira, que devido às diferenças climáticas do território, desenvolveu-se mais rápido no sul do que norte. O comércio da Mata está voltado para a

\footnotetext{
${ }^{4} \mathrm{O}$ mote é um verso poético que apresenta e encerra em si mesmo um ponto-de-vista ou uma condição.
}

exportação de açúcar, o cultivo de mandioca, coco, laranja, tomate, manga, a produção de artigos de origem animal: leite, ovos de galinha e de codorna, e mel de abelha; nos últimos 12 anos, por incentivo dos governos de Luis Inácio Lula da Silva e de sua sucessora, Dilma Roussef, vimos um crescimento da indústria alimentícia. Aárea açucareira por excelência, no século XVII, era a várzea do Capibaribe, que dispunha de 13 a 14 engenhos, seguindo-Ihe à região do Cabo de Santo Agostinho, onde havia 16 engenhos. No final do século XVIII, essa área já tinha penetrado bastante o interior, onde hoje é denominado zona da mata.

A cantoria de pé-de-parede é uma reunião organizada em casa ou em um bar por um chefe de família ou pelo dono do estabelecimento comercial para ouvir versos poéticos, improvisados por uma dupla de cantadores. 0 pé-de-parede, assim chamado pelo fato de a dupla cantar rente à parede, é realizado aos sábados à noite e aos domingos à tarde, reunindo amigos, parentes e vizinhos, que são convidados pelo organizador e/ou pelo cantador responsável pelo evento. A sua realização está atrelada ao calendário agrícola da região, é dizer, é de agosto a dezembro - época da safra da cana-de-açúcar, quando há uma maior ocorrência de cantoria. No entanto, a sua organização e realização são marcadas por incertezas e improvisações, ou seja, no período da safra, época propícia para as brincadeiras, uma vez que "a turma tem dinheiro", não há nenhuma garantia que algum vizinho ou parente "colocará cantoria" em sua casa. Um ambiente (o quintal de uma casa/um bar), reconhecido como "celeiro de cantador" e/ou "ambiente de boas cantorias", pode ter intervalos de anos entre a realização de uma brincadeira e outra.

A cantoria é composto por três momentos: a abertura, no qual os poetas cantam, sobretudo, para agradecer o dono da casa/barraca pelo apoio à realização do evento, e também para fazer a propaganda da dupla enquanto bons cantadores; o elogio, que consiste no momento dos versos que louvam o nome de todos os convidados adultos presentes no ambiente, que por sua vez, devem pagar aos cantadores pelas estrofes enaltecedoras; e, por fim, os pedidos, momento em que os convidados são autorizados a solicitar modalidades poéticas e canção. Essas três etapas são intercaladas por pequenos intervalos de cerca de 10 a 15 minutos, durante os quais, se houver cantador profissional ou amador como convidado, continua a ter produção de versos.

Se recorrermos, por exemplo, ao início do século $\mathrm{XX}$, é possível perceber que, em obras de referência, o termo "cantoria", designando o embate entre dois poetas improvisadores, não era usual. Por exemplo, na edição de 1937 do Vocabulário Pernambucano, não há verbetes para os termos cantoria e cantador; em vez disso, há o seguinte apontamento para "desafio":

"o adversário retruca logo, levantando-Ihe o último verso da quadra (...) Em um desses desafios, nos nossos sertões, em que um dos cantadores não acudiu aos 


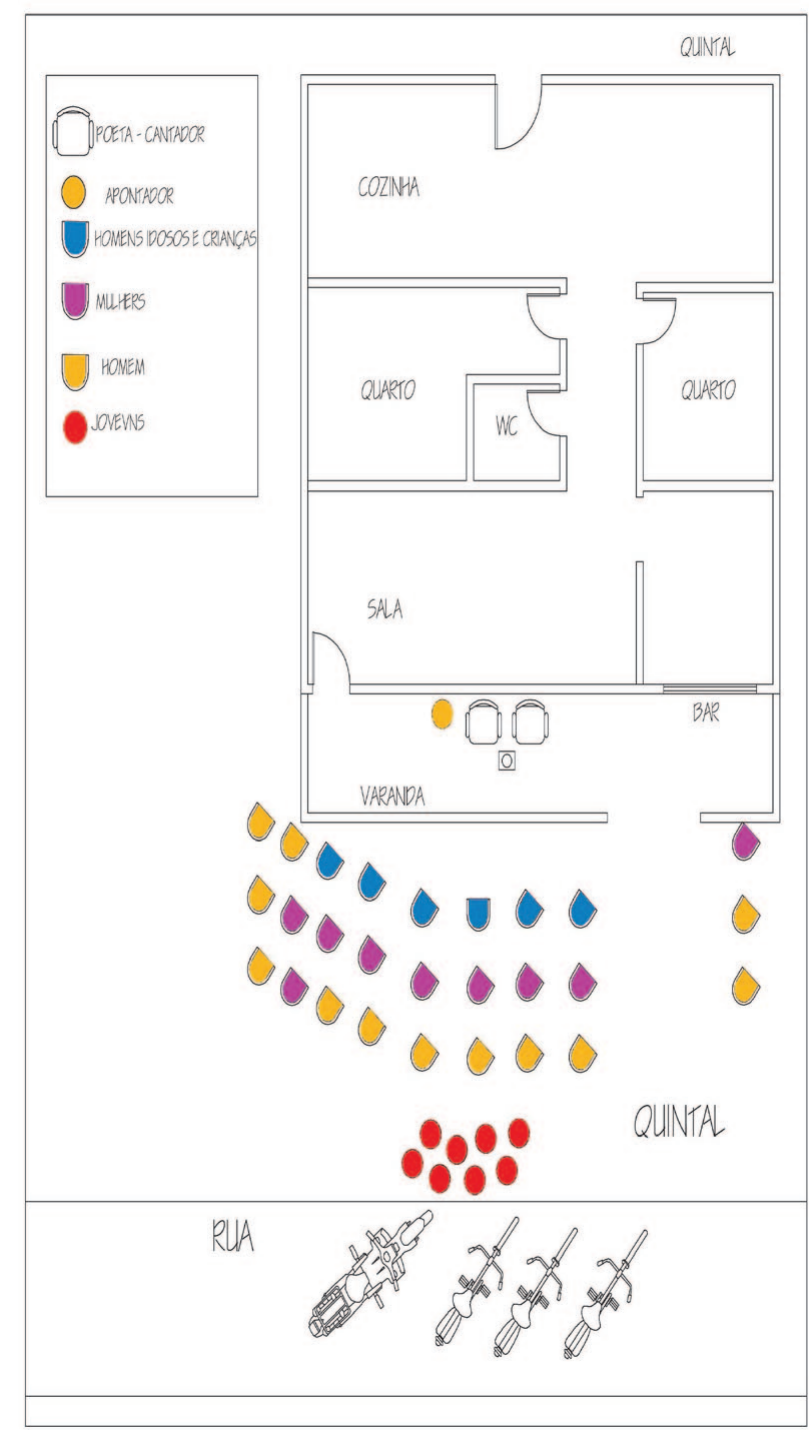

Figura 3. Planta da casa em dia de cantoria

Figure 3. House plan in singing day

versos atirados, o seu adversário investe-o com uns e depois outros, e sem resposta alguma rompe com estes, que pozeram termo ao prélio, pacificamente, graças à intervenção das pessoas presentes: "Cala a boca, bestalhão. Não soubeste responder? Metti-te o freio nos queixos, a sella mandei fazer." (Pereira da Costa, 1937)

Já na edição de 1976 do livro de Leonardo Mota, consta uma descrição da brincadeira via uma denominação do significado de cantador:

"Cantadores são os poetas populares que perambulam pelos sertões, cantando versos próprios e alheios; mormente os que não desdenham ou temem o desafio, peleja intelectual em que, perante o auditório ordinariamente numeroso, são postos em evidência os dotes de improvisação de dois ou mais vates matutos. Os gêneros poéticos de que comumente se socorrem os cantadores são as obras de seis pés, sete ou oito pés, o moirão, o martelo , a obra de nove por seus, a ligeira, o quadrão, o gabinete, o galope, a embolada e o dez pés em quadrão." (Leonardo Mota, 1976:03)

Semelhantemente a Pereira da Costa, Câmara Cascudo, no prefácio da edição de 1939 de Vaqueiros e Cantadores, refere-se à brincadeira como um desafio promovido para ver o embate de dois cantadores:

"Tios e primos eram vaqueiros e maníacos pelos cantadores. Sempre que era possível tínhamos um deles, arranchado, cantando. Pagavam $40 \$$ e com as louvações o cantador ia até $100 \$$. Fortuna. Mais raros eram os desafios sérios, as lutas tremendas entre poetas famosos. Vezes cotizavam-se todos os moradores e provocava-se o encontro. A tabela ia até $200 \$$ e mais ainda." (página 7. Prefácio do autor escrito em Natal em 1937).

Russel Parry Scott (1989) afirma em seu artigo que, durante o período que fez campo na mata pernambucana, entre 1977 e 1978, não havia nenhuma época em que os trabalhadores dos engenhos extravasassem coletivamente os conflitos latentes da estrutura hierárquica da plantation canavieira. Ele acrescenta que quando a cidade estava em festa, os trabalhadores nos engenhos seguiam com a sua rotina monótona do intercâmbio entre o período de safra e entressafra. As festas não passavam despercebidas por eles, mas o seu eco no cotidiano dos trabalhadores era tão frágil que não chegava configurar um hiato em sua rotina.

"No início do ano, o carnaval passava com pouca fanfarra nos engenhos e o mesmo acontecia com a páscoa e o tradicional ciclo junino de festas bem como com a época natalina e de ano novo...Por outro lado, havia festas ocasionais patrocinadas por uma ou outra figura de engenho (geralmente pertencente à hierarquia administrativa) que permitiam uma quebra de rotina, mas não era possível atribuir nenhuma sazonalidade ou repetividade anual na sua ocorrência. Eram eventos um tanto aleatórios." (Scott, 1989:120)

Ainda que o autor esteja descrevendo um contexto do final dos anos 1970, é possível perceber algumas continuidades, sobretudo no que tange à baixíssima celebração das festas de fim de ano. Entretanto, partindo da premissa de que festa é uma categoria etnográfica, é preciso fazer algumas ponderações acerca das observações de Russel Scott. Em primeiro lugar, é fundamental definir a perspectiva de tempo que se utilizará para pensar as práticas de improvisação, ou ainda, a discussão sobre as brincadeiras da zona da mata incidem necessariamente numa problematização da forma como o tempo é pensado e vivido nessa região. Devido às especificidades do material aqui analisado, privilegio nessa análise a concepção de tempo de Leach (1974) enquanto um dado que não existe em absoluto, marcado fundamentalmente pela "oscilação de opostos". O autor considera que a descontinuidade de contrastes repetidos é a forma mais elementar de todas as maneiras de encarar o tempo. Leach, desprezando a discussão filosófica acerca da natureza, busca, ao contrário, entender como a noção 
de tempo vincula-se às nossas experiências cotidianas. É exatamente sobre esse ponto que as noções de improviso e de brincadeira nos ajudam a esmiuçar, acredito eu, a noção de tempo na zona da mata. A conformação de um ambiente de cantoria e a sua vivência levam-nos a pensar o tempo mais como uma experiência do que pela concepção bergosoniana de duração. Dessa maneira, a ausência, eu diria aparente, do hiato e a aleatoriedade dos eventos reclamados por Scott se opõem a uma concepção de tempo, que parece presente em suas observações, como um fluxo objetivamente existente numa durée. Esse hiato dos ritos ordinários da vida cotidiana, na região, vai se conformar em brincadeiras, que é a própria poética e, sendo assim, para a sua devida compreensão, devem ser transformadas em eventos extraordinários. Além disso, as brincadeiras jamais podem ser traduzidas por certo sentido universal ou universalizante de festa, porque esta, para os próprios trabalhadores rurais da zona da mata, é um evento característico especificamente da cidade. Nos sítios, até os dias de hoje, o que há é brincadeira. Vale ressaltar que essa ideia de festa, enquanto elemento urbano e demarcado pelo calendário ocidental, não se restringe à região do nordeste brasileiro. Os antigos moradores de núcleos fabris ${ }^{5}$ do norte do estado do Rio de Janeiro região Sudeste do Brasil, por exemplo, consideram festa a "gratificação" ofertada pelo usineiro no fim do ano.

"Com uma visão pendular do tempo, a sequência das coisas é descontínua; o tempo é uma sucessão de alternações e paradas. Os intervalos são distintos, não como os marcos de sequência de régua de medida, mas como opostos repetidos, tique-taque, tique-taque. $\mathrm{E}$ nossas experiências mais elementar do fluxo do tempo são, certamente, desta espécie: dia-noite dia-noite; quente-frio quente-frio; molhado-seco molhado-seco." (Leach, 1974:206)

Nesse sentido, a brincadeira confere não somente o hiato da vida cotidiana, a partir de pares como submissoautônomo submisso-autôno, cabra-homem cabra-homem, verão-inverno verão-inverno, como em si é a própria percepção da alternância e do fluxo da vida.

Desde os trabalhos dos folcloristas, a categoria nativa brincadeira vem sendo amplamente resgatada e proliferada na literatura historiográfica, sociológica e antropológica, entretanto carece ainda de um minucioso exame para sua melhor compreensão e, sobretudo, das relações que a mesma reifica. Analisando-a brevemente pelas características circunstanciais da cantoria, diria que o objetivo de sua ação ritual em muito se assemelha ao dos Mianmin (Strathern, 2006):

"...os Mianmin agem num contexto de incerteza quanto

\footnotetext{
5 Os núcleos fabris, como réplicas de pequenas cidades, reuniam um conjunto de serviços e uma infra-estrutura social - como escola, casas, igreja, comércio, cinema, ambulatório e equipamento de lazer e esporte. Eles se fizeram presentes nas mais de 200 usinas de açúcar e tiveram grande crescimento entre as décadas de 1930 e 1950. Sobre o assunto ver Campagnol, Gabriela (2008).
}

ao resultado, o que faz de cada performance também uma improvisação. Um resultado bem-sucedido pode ser julgado na própria apresentação, mas esta última só deve ser julgada pelos efeitos subsequentes, nas questões de longo prazo da comunidade." (Strathern, 2006:265).

A alusão à interpretação do ritual melanésio devese, sobretudo, às características que marcam essa performance: improvisação e incerteza, que, de forma semelhante, estão na base da concepção de brincadeira. Não estou pretendendo, com isso, resolver a questão. Ao contrário, estou sinalizando que, talvez, o caminho para uma teoria geral da brincadeira não esteja em achar a sua equivalência numa concepção universal ou nativa de festa, mas na análise da concepção nativa de improvisação, que marca as relações, o tempo e o espaço nesse universo.

No jogo incessante da repetição dos nomes e do desenvolvimento dos motes, o improviso temporário reafirma laços atemporais, sob o testemunho de amigos, parentes e vizinhos. Os versos criados na negociação entre cantador e convidado narram um conjunto de valores que compõem o ethos camponês. Dessa forma, narrase incessantemente sobre o "bom chefe de família", "o homem respeitado", "o pai excelente", "o homem valente", "a mãe protetora", "o amigo de confiança", "a mulher fiel", "a pessoa de cartaz", "o lugar bom para cantoria" e, sobretudo, sobre os homens, que nesse ambiente, em condições harmoniosas, jamais serão chamados de cabra. Frederico Pernambucano de Mello, em seu livro Guerreiros do Sol, propõe uma interessante diferenciação entre o povo da mata e o do sertão, baseando-se na monocultura e no trabalho na atividade açucareira. Essa comparação torna-se especialmente importante aqui uma vez que ela nos ajuda a entender o significado intrínseco à categoria "cabra", tão comumente usada no dia-a-dia da zona da mata pernambucana, mas ausente no contato direto do ambiente da cantoria. Segundo a análise do autor, "cabra é o homem de armas que possui patrão ou chefe, desempenhando mandados tanto de ordem ofensiva quanto defensiva." (p.68). As categorias que fazem contraponto à ideia de cabra seriam jagunço e, principalmente, cangaceiro. A oposição dessas categorias, que muitas vezes são utilizadas equivocadamente como sinônimos, se dá pela noção de chefe. No caso do cabra, diferentemente do jagunço, o chefe tem sentido personalizado. O cabra, como destacou Ariano Suassuna (citado por Frederico P. de Mello, 2011), "é o morador, amigo ou compadre do fazendeiro; a relação entre eles se estabelece por base não em sentido profissional, mas por respeitáveis razões de amizade ou gratidão." (p.74) Já o cangaceiro, personagem da vida social sertaneja, é a figura que se opõe às demais aqui citadas por não possuir patrão. Os homens do cangaço, menciona o autor, se denominam como "rapaz", sobretudo, em relação ao chefe do bando, abolindo assim uma ideia de submissão direta. O cabra, comparado ao cangaceiro, ocupa, segundo Frederico de Mello, uma posição bem menos prestigiosa antes os 
olhos do homem do nordeste. Em seu uso cotidiano atual, cabra abarca os homens que trabalham ou trabalharam na monocultura canavieira, não tendo relação direta com o manejo de armas, mas sendo parte central da relação de sujeição imposta pela economia açucareira da região. Ora, toda essa questão torna-se de grande importância para a nossa discussão visto que, no ambiente da cantoria, não há espaço para processos sociais em que as pessoas não são evidenciadas em sua plenitude. O próprio lugar onde a cantoria se realiza se transforma em "ambiente", para onde convergem inúmeros caminhos traçados pelos convidados que dele participam. Nesse sentindo, trato o "ambiente" como uma espécie de nó feito por linhas que vão além daquela casa e não se encerram em si mesmo (Ingold, 2015). Em dia de cantoria, o quintal passa a ser um ambiente, onde o tempo e as pessoas são improvisados num movimento que the é peculiar - o tempo suspenso.

As estrofes também podem destacar alguns assuntos que a rigor, numa esfera ordinária, seria complicado, mas que não o é em "ambiente" de cantoria e, sobretudo, sendo narrado pelo cantador - a pessoa autorizada a fazer graça com a questão. Certa vez no campo, presenciei uma cena em que risos se sobrepuseram à tradicional atenção silenciadora do pé-de-parede. O motivo pela excitação deveu-se ao fato de um dos cantadores ter improvisado jocosamente sobre um dos convidados presentes: um vizinho da casa onde ocorria a brincadeira. O senhor em questão, na ocasião com 80 anos, tinha acabado de se casar com uma mulher de 27 . Pela reação e comentários das pessoas da mesa na qual eu estava, ficou explícito que o fato vinha sendo motivo de comentários, fofocas e boatos. Vejamos abaixo alguns dos versos que, ao final de sua recitação, suscitaram infinitas gargalhadas.

Inácio Caqueira é um homem muito educado

A esposa foi embora

Ele está separado

Mas para ele como falta

Uma mulher do seu lado

Senhor Inácio é convidado

Para nessa festa ajudar

Se a mulher foi embora

Já tem outra no lugar

Que sabe dá mais carinho

abraçar e mais beijar

Inácio veio namorar

E a sua vontade é tanta

Sua esposa foi embora

ele a ama ...

Que carinho de mulher nova

Qualquer velho levanta

Inácio no meio do povo

Meu amigo está presente

Eu considero Inácio

Um senhor bem competente
Com uma garota nova

Eita que macho tão quente!

Ela é assanhadinha

E ele não está cansado

Se ontem estava sozinho

Hoje estava acompanhado

A nega tem muito fogo

E já deu um beijo colado

Inácio apaixonado

Eu acho que ele está certo

Ela é liberta de tudo

E ele também é liberto

Que o viagra de Inácio

Hoje está muito perto

(Heleno e Severino Soares)

Percebi que ao cantar o fato, o poeta tinha dado a possibilidade de todos comentarem, revelando ao mesmo tempo o conjunto de valores que estava em jogo. o gozo, dessa forma, estava não só na possibilidade de comentar livremente, a partir dos versos, mas de expressar a reprovação social sem censura e conflito. Assim, por um lado, o riso é a consequência do improviso tecnicamente bem feito, mas, por outro, é a experimentação do que está sendo cantado. Em cantoria, rir é essencialmente reprovar. Tendo a achar que alguns dos recursos poéticos empregados no repente, por exemplo, a paronomásia e a aliteração, que implicam numa aproximação entre som e sentido, condicionam o discurso a um âmbito mais familiar e ao humor, o que pode vir a ajudar a suavizar a crítica cantada. Talvez também seja por isso que essa função poética seja estruturante das falas privilegiadas e narrativas desse universo. Diferentemente do gênero poético egípcio descrito por Lila Abu-Lughod (1999) - ginnãwa (little song), usado majoritariamente para desopilar o sofrimento, ou seja, as pessoas cantam quando estão tristes, tornamse poetas na tristeza, a poesia do repente não está condicionada a nenhum estado emotivo específico.

Na região, os programas de cantoria das rádios locais tem uma ampla audiência e são muito apreciados; todas as emissoras, sejam elas AM ou FM, contam com pelo menos um programa semanal de poesia improvisada. Em geral, ele tem a duração de uma hora e vai ao ar nas primeiras horas da manhã. Todo programa de cantador tem pelo menos um poeta responsável, mas que semanalmente recebe a visita de muitos outros que desejam dividir o microfone e a atenção da audiência. Ao longo de uma hora, eles agradecem incessantemente às pessoas que organizam brincadeiras em casa, divulgam as suas agendas e enviam saudações a amigos e a fãs de cantoria. Em uma hora de duração, os programas recebem tantas ligações de ouvintes pedindo motes e canções que, vezes ou outra, o tempo torna-se insuficiente. Atualmente, esses programas recebem o apoio do comércio local e também do dono da rádio, que nas cidades estudadas são políticos locais (prefeitos ou deputados). Nos anos 1960, 1970, os 
sindicatos dos trabalhadores rurais eram os patrocinadores exclusivos desse tipo de programa, e, em contrapartida, os poetas "cantavam os sindicatos": desenvolviam glosas convocando "a turma" a se filiar ao sindicato de sua cidade e participar das mobilizações por melhores condições de trabalho para os agricultores. Nessa ocasião, o que já não ocorre nos dias de hoje, os ouvintes que desejassem ter um mote desenvolvido, tinha que enviar uma dada quantia à dupla que comandava o programa. A rádio Planalto AM, em Carpina, é conhecida por ter tido até 1991 os mais renomados programas de cantoria de toda região da Mata e do agreste pernambucano ${ }^{6}$. Lá, segundo muitos cantadores, reuniam-se os mais célebres poetas. Sinésio Pereira, um dos poetas com os quais trabalho, esteve à frente daquele que foi um dos programas mais conhecidos no contexto da poesia da mata e do agreste pernambucano - Acorda Camponês! O referido programa de cantoria nasceu de um projeto do governo do estado, no segundo mandato do então governador Miguel Arraes (1987-1991), idealizado pelo jornalista Luís Sarino. Nesse período, Sinésio já era reconhecido como um cantador profissional, de renome e com uma quantidade expressiva de ambientes (quintais de casa) para cantar. Apesar da grande audiência do programa, que ia ao ar aos domingos de cinco às seis da manhã, o cantador, depois de dois anos, foi obrigado a deixar o "Acorda Camponês" e também a parar de cantar, devido a uma série de ameaças que vinha sofrendo. Os fatos contados por Sinésio em muito lembram o que Platão definiu como dever do Estado, em A república, ou seja, a vigilância da cidade que está cheia de "fabricantes de narrativas".

"Quando a gente entrava no ar, a abertura era essa: estamos apresentando o Acorda Camponês. Cinco horas da manhã, acorda camponês!

Aparentava que nós estávamos mandando ele acordar; Estamos apresentando o Acorda Camponês

Se uma hora fosse um dia

Se um dia fosse um mês

Não daria para falar

Nos problemas de vocês

Acorda Camponês

O pessoal vê logo que entra diferente. Vamos ao engenho tal, de tal cidade, temos denúncia do sindicato que aconteceu isto, isto e isto. Coisas contra os trabalhadores. Eles [referindo-se aos jornalistas: Luís, Ariano e Lúcia] apresentavam os problemas e eu fazia as estrofes cantadas ao som da viola. Não tinha nada de preparo. O cara estava dizendo e eu estava jogando lá. Cantando de improviso, perguntando ao senhor de engenho, ao barraqueiro, se fosse ele que estivesse no lugar do trabalhador, sofrendo o que o trabalhador sofre, como eles se sentiriam? Eu batia com o pessoal de um modo em geral. Mas sem atingir a integridade física, nem moral. "

\footnotetext{
6 Além das cidades da mata centro-norte vizinhas à Carpina, a freqüência da Rádio Planalto alcançava Surubim, Catolé de Casinha, Chatinha, entre outros lugares já no agreste pernambucano.
}

Sinésio começou a perceber que deveria sair do "Acorda Camponês" e o deixou quando recebeu uma carta de um senhor de engenho, pedindo-Ihe que fosse até a sua casa para tratar uma cantoria. Desconfiado, o cantador pediu a um amigo que lhe acompanhasse; chegando lá, um dos empregados atendeu-o na porta mesmo, transmitindo o recado do patrão:

"Olhe, você faz aquele programa "Acorda Camponês". Estou lhe dando um recado, senhor Amaro Dutra mandou dizer a você que, se estiver morrendo de fome, mande buscar a sua feira todo mês no engenho dele, mas saia do programa para não custar muito caro a você".

Semelhantemente, quando o senhor José Antônio da Silva publicou o poema "Moagem", explicitado no começo do artigo, o proprietário da antiga Usina Matary Ihe chamou para uma conversa e disse assim: "Que isso, rapaz, você escreveu uns versos dizendo que a sua vida aqui foi amarga, que eu tratava mal os meus funcionários. Seus pais moraram anos aqui, rapaz." O poeta, bastante contrariado pelo fato de ter tido que se explicar pelo poema, disse assim: "Ele queria que eu dissesse que a vida na Usina, Simone, era doce. Era tudo uma maravilha. Não era, né? Não é". Como já muito bem explicitada pela bibliografia sobre o trabalhador da cana dessa região, o que o patrão reivindica ao poeta, ao dizer que "os seus pais moraram aqui", é a dádiva intrínseca nesse tipo de relação de trabalho; é a perpetuação eterna da dívida do trabalhador/morador para com aquele que the "deu a morada" (Sigaud, 1979).

A habilidade de improvisar e/ou de jogar com formas linguísticas, além de ser altamente admiráveis, concede aos poetas uma legitimidade para tratar de assuntos de natureza diversa, sendo muitos deles, às vezes, embaraçosos. A poética, ao contrário do giñawa egípcio, não é um meio de intermediação direta de relação amorosa. Enquanto discurso emotivo, ao contrário, ela aponta para o modo pelo qual a vida social é por ela afetada. Ao contrário do que ocorre entre os Nhambiquara, segundo a descrição de C. Lévi-Strauss (1955), em uma cantoria de pé-de-parede, a revelação do nome próprio é obrigatória e compreende, assim, o cerne da reunião que tende destacar e distinguir. A exposição do nome, feita de forma incisiva e repetitiva, revela, assim, um momento de classificação e reafirmação daquelas pessoas.

O repente cotidiano, para além do "ambiente", foi muitas vezes descrito como uma forma de driblar o estado de desânimo desencadeado pelo cansaço físico em decorrência do trabalho no corte da cana ou do processo de descasque da mandioca para o preparo da farinha. Uma maneira de distrair o limite de seu próprio corpo. A poesia materializada no pedido de um mote pode também ser lida como expressão de saudade, de indignação, de sarcasmo ou como resposta a um conflito, etc. O ziguezague da roça e dos versos, ou seja, as alternâncias repetitivas da vida ordinária, implica num tempo marcado por incertezas e 
dúvidas. No entanto, essas incertezas ganham contornos perceptíveis na transformação de um espaço ordinário - o terreiro de casa - em um ambiente onde cabras passam a ser homens. Assim, os intervalos entre um ambiente e outro, entre uma safra e outra, entre um verso e outro são a possibilidade para a infinitude de sentidos. Para concluir, a repetição da vida cotidiana é ressignificada num intervalo que, como bem apontado pelo senhor Raimundinho, garante que haja versos e coentro até o próximo verão.

Rio de Janeiro, maio de 2016

\section{Bibliografia}

Austin, J.L. 1962. How to do things with words. Harvard: President and Fellows of Harvard College.

Abu-Lughod, L. 1999. Veiled sentiments: honor and poetry in a Bedouin Society. University of California Press.

Abu-Lughod, L.;C. Lutz. 1990. Language and the politics of emotion. Nova York : Cambridge University Press.

Agamben, G. 1999. Ideia da prosa. Lisboa: Edições Cotovia.

Arantes, A. A. 1982. O trabalho e a fala. São Paulo, Campinas: Editora Kairós, FUNCAMP.

Azevedo, D. 2011. "Nas redes dos donos da brincadeira: um estudo do mamulengo da zona da mata pernambucana". Dissertação. Programa de pós-graduação em Cs. Sociais em Desenvolvimento, agricultura e sociedade/CPDA/UFRRJ, Rio de Janeiro.

Bianchi, L. 2001. "Porto Seguro, berço da nacionalidade brasileira". Dissertação de mestrado apresentada ao Programa de Pós-graduação em História Social, Rio de Janeiro, UFRJ.

Carneiro, R. C. 1971. "Folhetos populares na zona do açúcar de Pernambuco." In: Cavalcante Proença \& outros (orgs). Literatura de cordel. São Paulo: ECA/USP.

Cascudo, L. C. 1939. Vaqueiros e cantadores. Porto Alegre: Edição da Livraria do Globo.

Elias, N. e Dunning E. 1992. A busca da excitação. Tradução: Maria Manuela Almeida e Silva. Lisboa: DIFEL.

Foucault, M. 1996. A ordem do discurso. São Paulo: Loyola.

Garcia J., Afrânio R. 1989. "Senhores e Moradores: a dependência personalizada". O sul: caminho do roçado. Estratégias de reprodução camponesa e transformação social. São Paulo: Editora Marco Zero, Brasília: Editora Universidade de Brasília: MCT-CNPQ.

Gell, A. 1995. "The language of the forest: landscape and phonological iconism in Umeda". In: HIRCH, E. \& OHANLON. The Anthropology of landscape: perspectives on place and space. Oxford: Claredon Press.

Godoi, E. P. e outros (orgs.). 2009. Diversidade do campesinato: expressões e categorias. Vol. I. Construções identitárias e sociabilidades. São Paulo: Editora UNESP.

Goody, J. 1987. "Oral composition and oral poetry", "Literacy and the non-literate: the impact of European schooling", "Memory and learning in oral and literate cultures: the reproduction of the Bagre", The interface between the written and the oral. Cambridge: Cambridge University Press.
Herzfeld, M. 1985. The poetics of manhood. Contest and identity in a Cretan Mountain village. New Jersey: Princeton University Press.

Ingold, T. 2015. Estar vivo. Ensaios sobre movimento, conhecimento e descrição. Petrópolis: Editora Vozes.

Jakobson, R. 2001. Linguística e comunicação. 24.ed. São Paulo: Cultrix.

Katell, M. 2013. "Em forêt, la musique: entre inquiétude et sentiment d'intimité (Goggam, Ethiopie)". In: Etnográfica. Vol 17 (3), Lisboa: Lodel. pp. 561-579.

Leach, E.1974. Repensando a antropologia. São Paulo: Editora Perspectiva.

Leite Lopes. J. S. 1976. O vapor do diabo. O trabalho dos operários do açúcar. Rio de Janeiro: Paz e Terra.

Lévi-Strauss, C. 1996. Tristes Trópicos. São Paulo: Companhia das Letras.

McCallum, C. 1998. "Alteridade e sociabilidade Kaxinauá: perspectivas de uma antropologia da vida diária". In: Revista Brasileira de Ciências Sociais, vol. 13, no. 38, São Paulo. Página do Scielo.

Mauss, M. 2003. "Ensaio sobre a dádiva. Forma e razão da troca nas sociedades arcaicas". Sociologia e Antropologia. São Paulo: Cosac\&Naif.

Mello, F. P. 2011. Guerreiros do sol: violência e banditismo no Nordeste do Brasil. São Paulo: A Girafa.

Perez, L. e outros. 2012. Festa como perspectiva e em perspectiva. FAPERJ, Garamond universitária, Rio de Janeiro.

Scott, R. P. 1992. "O dia do pagamento e o fim de semana: salários e a transformação dos rituais anuais de conflito na Plantation". In: Anuário Antropológico, 89: 117-129.

Prado, R. 2007. Todo ano tem. As festas na estrutura social camponesa. Coleção Antropologia e campesinato no Maranhão. São Luís: EDUFMA.

Radcliffe-Brown, A.R. 1973. "Parentescos por brincadeira". Estrutura e função na sociedade primitiva. Petrópolis: Editora Vozes.

Sigaud, L. 1979. Os clandestinos e os direitos. Estudo sobre trabalhadores da cana- de-açúcar de Pernambuco. São Paulo: Duas Cidades.

Silva, S. 2010. "A gente não esquece porque sabe o que vai dizer" Um estudo etnográfico da cantoria de pé-de-parede da zona da mata de Pernambuco. Tese apresentada ao PPGAS, Museu Nacional/UFRJ, Rio de Janeiro.

Silva, S. 2002. "As rodas literárias nas décadas de 1920-30. Troca e recriprocidade no mundo do livro". Dissertação de mestrado apresentada ao Programa de Pós-graduação em Antropologia Social do Museu Nacional, Rio de Janeiro, UFRJ.

Strathern, M. 2006. O gênero da dádiva: problemas com as mulheres e problemas com a sociedade na Melanésia. Campinas: Editora da Unicamp

Turner, V. 2008. Dramas, campos e metáforas. Ação simbólica na sociedade humana. Niterói: Editora da Universidade Federal Fluminense.

Yacine, T. 2011. "L'art de dire sans dire em Kabylie". In: Cahiers de littérature orale, 70, Paris: INALCO. 